\title{
Decot, Rolf, Arnold, Matthieu, Christen und Juden im Reformationszeitalter
}

Claire Ravez

\section{OpenEdition}

Journals

Édition électronique

URL : http://journals.openedition.org/ifha/1674

DOI : $10.4000 /$ ifha. 1674

ISSN : 2198-8943

Éditeur

IFRA - Institut franco-allemand (sciences historiques et sociales)

Référence électronique

Claire Ravez, "Decot, Rolf, Arnold, Matthieu, Christen und Juden im Reformationszeitalter », Revue de I'IFHA [En ligne], Date de recension, mis en ligne le 01 janvier 2008, consulté le 22 septembre 2020. URL : http://journals.openedition.org/ifha/1674 ; DOI : https://doi.org/10.4000/ifha.1674

Ce document a été généré automatiquement le 22 septembre 2020

(CIFHA 


\title{
Decot, Rolf, Arnold, Matthieu, Christen und Juden im Reformationszeitalter
}

\author{
Claire Ravez
}

Seize contributions (onze en langue allemande et cinq en français) complétées par un avant-propos et une introduction rédigés par les responsables de la publication composent ce recueil, enrichi d'un index et surtout d'une imposante bibliographie générale en fin d'ouvrage (p. 279-308). Ces contributions sont le fruit d'un colloque international organisé à Strasbourg en 2005 ; plus que d'ouvrir de nouvelles pistes de recherche sur le sujet des relations entre chrétiens et juifs à l'époque de la Réforme, leur combinaison permet de confronter des résultats déjà obtenus dans divers champs de recherche, dans le but de mettre en valeur points communs et différences entre auteurs, confessions et religions. L'approche comparative, qui permet au lecteur de se rendre compte des usages rhétoriques communs du thème juif dans les discours confessionnels naissants n'exclut cependant pas d'autres approches du sujet, comme l'historiographie ou les procédés d'autoperception de la communauté juive.

Cinq ensembles se distinguent de façon logique dans l'architecture d'ensemble de la publication. À une première section sur les rapports des théologiens de la Réforme à la religion juive (mise en valeur de la diversité des Propos de table de Luther par N. de la Harpe, plaidoyer pour une étude de la Wirkungsgeschichte des écrits de Luther par M.A., relecture de la biographie de Calvin par A. Detmers, contraste chez Martin Bucer entre connaissances vétérotestamentaires et attitude envers ses contemporains par A. Noblesse-Rocher, mise au point sur la faible influence directe de juifs sur les anabaptistes sabbatéens par $\mathrm{M}$. Rothkegel) succèdent un pendant pour les hommes d'Église catholiques (Eck et ses écrits par J. Brosseder, la politique pontificale de Contre-Réforme par A. Prosperi) et une analyse des relations entre communautés (deux articles de F. Raphaël et M. Ebstein permettent de redécouvrir l'action de Joselmann de Rosheim à la cour impériale, un sermon de mission est analysé par A. Lehardt, la réception dans l'historiographie juive allemande naissante du jubilé de 1817 est analysée par M. Pyka). Deux sections complètent le cœur de l'ouvrage : l'une le replace 
dans les cadres politiques de l'Empire (J. F. Battenberg sur le statut juridique de la communauté juive et R. D. sur les juifs de Mayence à l'époque moderne), l'autre fait découvrir au lecteur les points de vue des Églises orthodoxes (la perception du judaïsme en Russie au XVIe s. - M. V. Dmitriev -, l'intérêt porté aux juifs karaïtes par les théologiens chrétiens au cours de l'époque moderne - M. Kizilov -, le travail du philosophe juif Leon Chestov sur l'œuvre de Luther - D. Belkin).

Il s'agit donc avec cet ouvrage d'une synthèse réussie, aux contributions instructives produites par des auteurs d'horizons variés, auquel il ne manque qu'une conclusion pour fixer les résultats de cette mise en perspective spatiale et temporelle des relations entre chrétiens et juifs au seuil de l'époque moderne.

Claire Ravez (Lycée Fabert, Metz) 